\title{
Funding E-Health in Nigeria by NGOS/Multinational Organization: Overview and Perspectives
}

\author{
Edje E. Abel, M.Sc \\ Information Systems Management \\ Department of Mathematics and Computer \\ Science \\ Delta State University, Abraka \\ P.M.B. 01 \\ Delta State, \\ Nigeria.
}

\author{
Ekabua Obeten, Ph.D \\ Software Engineering and Systems \\ Department Mathematics and Computer Science \\ Delta State University, Abraka \\ P.M.B. 01 \\ Delta State, \\ Nigeria.
}

\begin{abstract}
Electronic-Health infrastructure tends to improve the quality of healthcare service delivery through timely access to information electronically with the aid of internet. Mmillions of people in the developed world use internet as a source of healthcare information to improve their lives. Despite the benefits of e-health infrastructure, people living in developing countries lack access to timely information and poor ehealthcare services. Foreign Ngo's and Multinational institutions (e g. world health organization) have been involved in the funding of e-health projects in some developing countries such as India, Uganda, Rwanda, Zambia and Ethopia e $t \mathrm{c}$. In the case of Nigeria, these same organizations hardly fund or support the implementation of ehealth project. The factors preventing foreign NGOs and Multinational institutions from funding e-health projects in Nigeria were investigated. Data was obtained by conducting Semi-structured interview on prospective individuals of interest and from related academic journal papers. Individuals interviewed include, officials of World Health Organization (WHO), International Monetery Fund (IMF) and Swedish Support ICT Programs in Developing countries (SPIDER). Findings shows that lack of cooperation among healthcare stakeholders, political will and cultural barriers are some of the major factors preventing these Organizations from funding e-health projects. Recommendations were put forward in other to attracts these organizations to fund e-health projects in the conutry. Some of these recommendations include educating healthcare stakeholders what e-health is about, embarking on a sensitization program in the local, state and federal level.
\end{abstract}

\section{Keywords}

The Drug Logistic Information and Management System (DLMS), Open Medical Records System (OMRS) ,MammoGrid (MG), Mobile Community Based Surveillance (MCBS), Information and Communication Technology (ICT)

\section{INTRODUCTION}

Everyone speaks of e-Health these days, yet only a fraction of people in the medical sector and computer technologists have come up with a vivid definition of this emerging term. WHO [1] defined e-health as the combine use of electronic Information and Communications Technology (ICT) in the health sector for clinical, educational, research and administrative purposes, both at the local and distant region. It is difficult and annoying for a patient to travel a long distance under bad weather conditions just to book an appointment with a doctor. For instance, in the Nigeria scenario patients have to wait in long queues just to be seen by the doctor for advice; thus may even contract diseases in the waiting rooms.
By utilizing e-Health, patients can get treatments sitting at home without going through all these tedious process [2].

According to [3], e-Health is the embryonic convergence of wide-reaching technologies like the internet, computer telephony interactive voice response, wireless communications and direct access to healthcare providers, care management, education, and wellness. Healthcare services and information such as the treatments and awareness of a particular disease (e g. Malaria), can be delivered through computer telephony, internets and other forms of electronic communication devices to patients around the globe efficiently.

e-Health includes a broad range of implements, such as electronic health records, information gathering software, mobile devices, e-learning tools and horizon technologies that defy human imagination [4]. With the collective use of these implements, health inequalities between the rich and poor can be reduce drastically, and healthcare providers will be equip to make decisive decision for treatments. For instance, a doctor in a remote area (e g. village) can access information via his laptop or mobile phone on the finest treatments. Also, the option of longitudinal electronic health records can be used by doctors and healthcare providers to fast track treatment of patients [4].

\section{BRIEF HISTORY OF e-HEALTH}

e-Health is beleived to have started in the early eighties, when professional healthcare practitioners and institutions in the developed world attempted to adopt integrated clinical workstations. [5] stated that, these workstations were single entry points into the medical system, in which computational tools assisted not only with clinical matters, but also with administrative and financial (e g. Payroll) affairs. Examples of administrative task include appointment booking of patients to see their doctors and transfer of patient data from one hospital to another e t c. The workstation consists of a medical record system which is accessible electronically, in a confidential and secure manner that is acceptable to patients and healthcare practitioners [6].

Over the last decade to date, e-Health has advanced from a mere patient recording system to the use of internet and computer network infrastructures in healthcare service delivery. Healthcare institutions, practitioners and patients are becoming more willing to use the internet and other web applications. This has opened a new aspect in healthcare service delivery. [7] reproted that many surveys have indicated that more patients are surfing the internet to access healthcare information, services and advice on particular diseases, treatments and improving their own health 
management. Also, healthcare practitioners are using webenabled applications to monitor vital signs for enhancing healthcare delivery and assist clinical decision making as well as managing diseases. Examples of some of the successes recorded include the use of web-enabled applications by healthcare practitioners in china to carry out cancer research. It was implemented by integrating the web portal into the national database system, to enable the monitoring of cancer treatment and sharing of new discoveries. Another new development in electronic-Health is the application of grid computing to support healthcare services. An example of such development is the introduction of MammoGrid. MammoGrid enables huge volume of data (images) associated with regional breast cancer screening programmes to be available across multiple medical centers at an acceptable time [8]. Images collected after screening of patients with breast cancer are stored in a large database to be distributed to two or more medical centers electronically. This, allows clinicians to collaborate in the analysis of mammography (image) data. It also enable them to have quick access to large volume of medical image data to carry out advance image processing, radiographic education and most importantly telediagnosis across medical communities, "i.e. groups of medical practitioners and organizations that are detached both regionally and geographically but working together by using the shared resources of the Grid" [9]

\section{BENEFITS OF e-HEALTH}

The introduction of e-Health in the healthcare sector has made a positive impact on healthcare delivery. Catwell [10], attest to this fact in their report which states that e-health improves the efficiency of recording, storing, retrieving and sharing of patient information both within and between various stakeholders. In other words, it enables timely access to patient's data for analysis in order to improve the delivery of healthcare services. This means that clinicians and doctors do not have to waste their time browsing through manual files and documents in search of patient's information. Also, it relieves the pressure of documenting patient data manually as well as preventing it from unauthorized persons.

Electronic-Health tends to reduce the increasing number of patients who are accidentally harmed due to medical errors and violations, [11]. Errors such as mistaken patient information for another can be reduced drastically, with the application of e-health systems in the healthcare sectors; thus enhancing the uniqueness of a patient's medical information for safety purposes.

Another benefit of e-health is that "it offers the potential for enhanced reach, including traditionally underserved populations, at relatively low cost, and the capacity to provide tailoring and customization for individual patients and consumers" [12]. For instance, people (e g. incapacitated individuals) who cannot embark on a long distance journey from home to hospital for medical checkups can have timely access to healthcare services at an affordable cost via internet and other electronic means in their homes.

e-Health enhances the quality of healthcare delivery services [13]. For instance, it allows comparisons between various healthcare providers, thereby enlightening patients about the best quality healthcare providers to seek for medical treatments. e-Health also encourages quality relationship between healthcare practitioners and patient towards a true partnership, where decisions are made and agreed upon in a shared manner [14]. In other words, decision making by healthcare practitioners are proven to be valid and reliable, base on shared information with patient before medical treatments.

\section{4. e-HEALTH PROJECTS IN DEVELOPING COUNTRIES FUNDED BY FOREIGN NGOS AND MULTINATIONAL INSTITUTIONS}

Over the past ten years there has being a tremendous number of e-Health projects implementation in developing countries. Most of these projects are been funded or sponsored by foreign NGOs, multi-national or international institutions (e.g. World Health Organization, and International Monetary Fund etc). A typical example of such project is the implementation of high speed hospitals in Ethiopia. This project was set up by Indian technicians and funded by Indian aid. The purpose was to enable ultrasound image of babies to be taken from pregnant women. The images were then forwarded to a computer screen. What is special about this project is that, as the image appears on a computer screen at Addis Ababa Hospital in Ethiopia, it appears simultaneously on a similar computer screen at the Care Hospital in Hyderabad in Southern India [15]. Thus, doctors in both countries can share ideas and analyze the image together.

The FP6 (Sixth Framework Programme) of European Commission with the Malaysian Government funded a national hospital information system project in Malaysia. The system was designed to handle administrative task, drug inventory management, finance, and health management information reporting, as well as ambulance dispatch information management" [16]. It was reckoned that once a driver had sent a patient to the hospital, he would log onto the system to record the route and traffic information for analysis in order to strategize a new means of transporting patients to the hospital quickly and efficiently.

In Rwanda, Spider (Swedish support ICT programs in developing countries) in conjunction with the Rwandan Government funded the implementation of an electronic information system called TRACnet. This system allows the people of Rwanda involved in anti-retroviral treatment (e g. HIV/AIDS) programs to electronically submit reports and have timely access to vital information, [17]. The drug Logistic Information Management Systems have just been implemented in India which was sponsored by InterSystems Corporation (a private software company) based in the United State of America. The drug logistic information and management system (DLMS) handles procurement, storage and the distribution of drugs and other medical equipments to college hospitals and community health centres in the state of Gujarat, [18]. It is said that the system monitors demands and the availability of medical goods in stock, thereby generating payment orders and sending orders to suppliers, as well as updating goods in stock automatically.

\section{5. e-HEALTH PROJECTS IN NIGERIA}

Nigeria which has the largest population (estimated to be 150 Million) in Africa, is initiating e-Health infrastructure platform. It is reckoned that there is no major e-health (e.g. national healthcare information system) projects that are being implemented in the country hence medical practitioners depends on paper based system. This has posed a huge burden to clinicians and medical practitioners as they rely heavily on ineffective paper based manual system. According to [19], 500,000 women die due to complications from childbirth in the world, of which $10 \%$ of that figure is from Nigeria due to lack of ineffective data management. 
Currently, the Nigerian Government is embarking on the implementation of OpenMRS (Medical Records System) for maternal and child healthcare. It is believed that the system will be built in low-power computing facilities that will be able to run for eight hours without generator power. In addition, its main source of power will be from low-cost solar panels, and will be synchronized between implementations and a central server on or off-line [20]. It will provide timely and accurate information needed to manage facility planning (i.e. drug ordering), influence funding and policy decisions, as well as providing clinicians with patient histories that they can use to improve decision making before, during and after labor/delivery [21].

The completion of Mobile Community Based Surveillance (MCBS) e-Health project implemented by the Nigerian government. This MCBS project was designed to give traditional birth attendants the ability to report vital maternal and child health events in real time using mobile phones [20]. It allows traditional birth attendants to send text messages via mobile phones to health officials within the community when witnessing a vital maternal health event. The system is said to minimize the delay in receiving maternal care, as it enables health officials or midwifes to respond quickly to the event.

There are other e-Health initiatives which are yet to be implemented due to lack of funds. It is reckoned that the Nigerian Government is in search for sponsors that can assist in the funding of these projects as it cannot rely on its annual revenue. Presently, there is no e-Health project that is been funded by foreign NGOs or multi-national/international institutions in Nigeria, other African countries.

\section{FACTORS PREVENTING FOREIGN NON-GOVERNMENTAL$$
\text { ORGANIZATIONS AND }
$$$$
\text { MULTINATIONAL INSTITUTIONS }
$$$$
\text { FROM FUNDING e-HEALTH }
$$$$
\text { PROJECTS IN NIGERIA }
$$

Lack of cooperation among healthcare stakeholders discourages foreign NGOs from funding e-health projects in the country. Do-it-alone attitude of healthcare stakeholders does not permit operations on meaningfully and substantive scope but rather on small, experimental and limited basis [22]. Most healthcare stakeholders in the country put personal interest above collective interest. Disagreement among healthcare stakeholders is the norm of the day. The inability of healthcare stakeholders to put personal interest aside prevents foreign NGOs and international institutions from funding e-health projects in the country, because they regards such attitude as unhealthy, irrational and will not benefit the generality of the populace.

Inadequate basic healthcare infrastructure (standard hospitals) preventing the funding of e-health projects. Most people living in the rural area believe that the funding of basic healthcare problems (e g. clean water, Vaccination and primary healthcare centres) is more beneficial and economically reasonable compared to some e-health projects. This notion and ideology of the people, often demoralises and prevents prospective foreign $\mathrm{NGOs}$ and multinational institutions that have the intention of funding e-health projects in these rural areas. These Organization would rather implement projects that meets the basic needs of the people e .g access to clean water.
Poor supervision of healthcare Information Technology. Health Information technology in the country is often implemented at a very basic level by private hospitals without adhering to any specific standards. There is no effective system for supervision of healthcare services in the public and private sector by the government [23]. The atitude of private hospitals and individual healthcare organizations in the country in implementing e-Health Decision Support Systems in isolation, prevents NGOs from assisting in funding such projects. The Swedish Program for ICT in Developing Countries believes that funding such projects will only benefit these private hospitals that rely heavily on profit making.

Lack of political-will from government also prevents foreign NGOs from funding e-health project in Nigeria. e-Health policy is limited in capacity and ineffective which is mostly managed by established private healthcare institutions, that have lobbied their way through, by simply offering some cash to some government personnel in the country. These established healthcare institutions charged with the obligation to manage e-health policy, often divert the fund meant for ehealth project to fund their own private healthcare establishments. They achieve this by initiating a white elephant healthcare project (such as vaccination exercise) without implementing it just to deceive healthcare stakeholders and the populace.

Another issue is the lack of e-health initiative by healthcare policy makers. Although, policy makers in the country are aware of the benefits of e-health, due to some factors they are reluctant to initiate e-health projects in their policy. These factors are mostly stem from the problem of primary healthcare (e.g. clean water, sanitations e t c) which is prevalent in the country.

Precarious economic position of Nigera also prevent these Organization from fund e-health projects. Most multinational and international institutions such as the European Union do not include Nigeria in their agenda. They are of the opinion that Nigeria as a country is not as poor as other developing countries such as Malawi, Ethiopia and Tanzania e t c. Also, they often hold on to the view that Nigeria is buoyant enough financially to fund e-health projects. This is due to the fact that Nigeria is the $9^{\text {th }}$ major crude oil and gas exporter in the world as of the year, 2009.

Imposition of government control over foriegn sponsored project. The government considers that it is their legitimate right and responsibility to control and regulate the role of these multi-national/international institutions for sponsoring e-health project in the country. Multi-national/international institutions or foreign NGOs find this act disturbing and uncomfortable; they reckon that it contravenes their own policies of assisting developing countries in the implementation of e-health projects [24]

Cultural barriers is also a major factor preventing these organisatoions. Accepting technological change is a very difficult process in every human society. The management of change is mainly uncomfortable when it relates to the elusive issue of health as some places in the country especially in the rural communities vary in the way they consider illness and medicine; due to cultural norms preventing categories of individuals from receiving medical treatment [25]. These cultural norms relate to gender bias and social status e $t \mathrm{c}$. Therefore, the issue of cultural factors explains the rejection of modern medicine that constitutes an obstacle for multinational and international institutions to fund or sponsor the implementation of e-Health systems projects in the country. 


\section{RECOMMENDATIONS}

The factors preventing multi-national institutions or foreign NGOs from funding e-Health projects in Nigeria can be addressed by expanding e-Health education in Local, States and Federal level. An orderly education in e-Health needs to be carried out for healthcare stakeholders and people living in the rural communities, by enlighten them the benefits of ehealth, technical needs and existing e-health applications. This will enable health practitioners and clinicians to adopt this new method.

Change in the atitude of policy makers and commitment from the government. They must be made to see the immense benefit of e-health, which are the key elements in bringing about changes in any country, most become evident to foriegn sponsors. In other words, The willingness of policy makers to use ICT in health is vital in integrating this tool into the health sector [26]. Also, foreign NGO's and Multinationals should embark on use of indigenous manpower such as medical practitioners and ICT experts for the implementation of ehealth projects in the country. The indigenous practitioners and ICT exparts have the wealth of knowledge and skill to make significant contributions and also they know the specific needs and cultural issues within host communities.

Foreign NGO's and Multinational institutions can also be attracted to fund e-health projects in the country by restructuring the healthcare sector. This can be done by setting up agencies in each of the three tiers of government. Whereby, the agency at the local level will be authorized to regulate the activities of healthcare issues. By providing medical and computer equipments to every public hospitals and compeling other private hospitals to collaborate with these public hospitals in the local area. Same should be done to the States and Federal level. This will provide a formidable collaboration of these agencies at the Local, States and Federal level.

The government should come up with polices that will give foreign NGOs or multi-national institutions the legitimate right to implement e-Health projects, as long as they make their initiative known. This will attract more foreign NGOs to fund e-Health projects in the country, and will enable people living in the rural and urban communities to have quick access to healthcare facilities. Also, initiate the collaboration between foreign NGOs and indigenous healthcare stakeholders in the country. This will drastically reduce the abandonment of e-health projects, leading to meaningful completion of such projects in the country. In the aspect of electricity power generation, which is a major problem in the country; an alternative power source such as solar energy should be made available to power hospitals. Also, in-built power storage for computers in every hospitals and healthcare institutions should be provided.

\section{CONCLUSION}

e-Health infrastructure will positively impact the health sector in Nigeria to deliver effective and timely healthcare services to her citizens. The need for public enlightenment and sensitization of government about this emerging technology in the health sector. How it could be of benefits to their wellbeing by facilitating treatments and timely access to accurate information about the cure on specific diseases, particularly to the less privilege; as it tends to reduce healthcare inequality between the rich and the poor. Government need to establish policies that will not only attracts these foreign NGO's or multi-national institutions to the country, but also see to it that these policies are implemented to the letter.
In the future, the researchers tend to embark on e-health project by formulating a Desktop Grid Computing architecture framework design, which will aid the speeding up of some medical processes. For instance, to forecast the number of patients that will undergo different treatments within certain period of time. So that all the necessary medical facilities (e g. drugs) needed for these treatments will be provided beforehand.

\section{REFERENCES}

[1] World Health Organization (2004), Bulletin of the World Health Organization, Volume No 82, Issue no 10 , Geneva. http://www.scielosp.org/scielo. [Accessed Date: 18-12-2012]

[2] Kaur G. and Gupta N. (2006), E-health: A new Perspective on Global Health, Journal of Evolution Technology, volume 15, Issue No 1, Page 23-35

[3] J. M. Deluca and Enmark R (2000). E-health: The Changing model of Healthcare, Front Health Services Manage, Volume 7, Issue No 1, Page 3-15 http://www.ncbi.nlm.nih.gov/pubmed/11184427 [Accessed Date: 26-11-2012]

[4] Silos to System, (2010). An Overview of health's Transformative Power, Bellagio Centre Conference, Rockefeller Doundation, New York, Unted State of America, Page 1-62

[5] Shortliffe H. E. and Friedman P. C., (1999). The Evolution of Electronic Medical Records, Journal of Academic Medicine, Volume 74, Issue No 4, Page 414419

[6] Shortliffe H. E., (1998). The Evolution of Electronic Health-Care Records in the Era of the Internet, Annual Symposium proceedings of the American Medical Informatics Association, Stanford University, United State of America Issue, Page 1-8

[7] Huang S., Hisa T.L., Tsai H.T. and Wu J. H., (2006). Revolution or Evolution? An Analysis of E-health Innovation and the Impact using a Hypercube Model, International Journal of Electronic Healthcare, Volume 2, Issue No 1, Page 1-47

[8] Rogulin D., Estrella F., Hauer T., McClatchey R., Amendolia S. R.and Solomonides T., (2004). A Grid Information Infrastructure for Medical Image Analysis, Proceedings of the Distributed Databases and Processing in Medical Image Computing Workshop, Bristol, West England, Page 1-10, http://www.irisa.fr/visages/demo/Neurobase/Didamic/d1 2.pdf [Access Date: 29-06-2010]

[9] Matysiewicz J. and Amyczek S. (2009). Consumer trusth Challenges of e-healthcare, Fourth International Conference on Cooperation and Promotion of Information Resources in Science and Technology, Poland, Page 1-6

[10] Catwell Lo. and Sheikkh A. (2009). Evaluating e-Health Interventions: The need for continues Systems Evaluation, Journal of Medical Internet Research, Volume 6, Issue No 8, Page 1-6

[11] Scott E. R. and Saeed A. (2008). Global e-HealthMeasuring Outcomes: Why, What, and How, A Report commissioned by the World Health Organization`s Global Observatory for e-Health, Page 1-28 www.ehealth-connection.org/.../Global\%20eHealth\%20$\% 20$ Measuring\%20Outcomes [Accessed Date: 28-062010] 
[12] Ahern K. D, Kreslake M. K. J. and Judith M P. (2006), What is eHealth: Perspectives on the Evolution of eHealth Resaerch, Journal of the Medical Internet Research, Volume 8, Issue No 1, Page 1-19, http://www.jmir.org, [Date Accessed: 12-05-2010]

[13] Eysenbach G., (2001). What is e-health? Journal of Medical Internet Research, Volume 3, Issue No 2. Page 3-20

[14] Anderson G. J. (2007). Social, ethical and legal barriers to E-health, International Journal of Medical Informatics, Volume 7, Issue No 6, Page 480-483

[15] Blunt E., (16-07-2007), Ethiopia`s High speed hospitals. http://news.bbc.co.uk/1/hi/world/africa/6295044.stm [Date Accessed: 20-06-2010]

[16] Li J., (2010). HealthCare: Building a Healthy Malaysia, http://www.futuregov.net/articles/2010/jan/07/buildinghealthy-malaysia/ [Date Accessed: 30-06-2010]

[17] Rwanda TRACnet, (2008). Rwanda Development Gateway

http://www.rwandagateway.org/article.php3?id_article=8 473 [Date Accessed: 30-06-2010]

[18] Di Girolamo A. M., Matranga Isabel.(2009), Exploiting Research INfrastructures potentiAl for boosting Research and Innovation in Africa (ERINA4Africa), Page 1-35

[19] World Health Organization, (2008). WHO Country Cooperation Strategy in Nigeria http://www.afro.who.int/index.php?option=com_content $\&$ view $=$ article $\&$ id $=1047 \&$ Itemid $=1936$ [Accessed Date: 23-08-2010]

[20] e-health Nigeria, www.ehealthnigeria.org/where-we-work/list-ofimplementations/, [Date Accessed: 03-05-2013]
[28] Drury P., (2005). e-Health: A Model for Developing Countries, eHealth International Journal Volume 2, Issue No 2, page 20-26

[29] Harno K., Nykänen P., Ohtonen J., Seppälä A. and Kopra K., (2009). Healthcare Information Exchange in Regional $e$ Health Networks Implications for Initiatives in Advancing Shared Care, International Conference on EHealth, Telemedicine and Social Medicine, Helsinki, Finland, Page 42-45 http://ieeexplore.ieee.org/xpl/freeabs_all.jsp?reload=true \&arnumber=4782630 [Date Accessed: 12-12-2012]

[30] Harno K., Routsalainen P., Nykanen P. and Kopra K., (2008), Migration from Regional to a National eHealth Network, Second International Conference on the Digital Society, Helsinki, Finland, Page 107-110 http://www.ieeexplore.ieee.org/xpl/freeabs_all.jsp?reload $=$ true $\&$ tp $=\&$ arnumber $=4456028 \&$ isnumbe [Date Accessed: 26-10-2012]

[31] Turisco F., Deutsch H., Lykke F., Berend D. and Spence A. (2009). Large-Scale e-Health Initiatives: Decision points and best practices. Business Solutions Technology Outsourcing, Massachusetts, United State of America. http://assets1.csc.com/health_services/downloads/CSC_L arge_Scale_eHealth_Initiatives_Decision_Points_and_B est_Practices.pdf [Date Accessed: 01-12-2012]

[32] Ure J., Hartswood M., Wardlaw J., Procter R., Anderson S., Gonzalez-Velez H., Lin Y., Lloyd S., Ho Kate, (2009).The Development of Data Infrastructures for eHealth: A Socio-Technical Perspective, Journal of the Association for Information Systems, Volume 10, Issue No 5, Page 415-429

[33] Wilson P., Leitner C. and Moussalli A. (2004). Mapping the Potential of e-Health Empowering the citizen through e-Health tools and services, Conference of E-Health, Republic of Ireland, Page 1-51

[34] World Health Organization, (2008-2013). WHO Country Cooperation Strategy in Nigeria http://www.afro.who.int/index.php?option=com_content $\&$ view $=$ article\&id=1047\&Itemid=1936 [Accessed Date: 23-11-2012]

[35] Sinha C. and Fraser H., (2010). Strengthening Health Information Systems to Support Post Disaster Healthcare in Haiti. http://www.idrc.ca/en/ev-155008-201-1DO_TOPIC.html [Date Accessed: 28-06-2010]

[36] Stroemann A. K., Jones T., Dobrev A. and Stroemann N. V., (2006). E-Health is Worth it: The Economic benefits of Implemented e-Health solutions at ten European sites, Information Society and Media of European Commission, Page 1-60 http://www.epractice.eu/files/eHealth\%20Impact\%20Eur opean\%20sites.pdf [Accessed Date: 29-06-2010]

[37] Huang S., Hisa T.L., Tsai H.T. and Wu J. H., (2006). Revolution or Evolution? An Analysis of E-health Innovation and the Impact using a Hypercube Model, International Journal of Electronic Healthcare, Volume 2, Issue No 1, Page 1-47

[38] Mazzetti P., Nativi S., Angelini V., Verilato M. and Fiorucci P., (2009). A Grid platform for the European Civil Protection e-Infrastucture: the Forest Fires use scenario, Journal of Earth Science Informatics, Volume Number 2, Page 53-62

[39] Michael W. (2001), What is e-Health? http://www.suite101.com/pages/article_old.cfm/e_health/ 57010 [Date Accessed: 18-06-2010] 